\title{
TEACHING TEAMWORK, ETHICS AND EQUITY, AND IMPACT ON SOCIETY AND THE ENVIRONMENT TO UNDERGRADUATE ENGINEERING STUDENTS: A REVIEW OF THE LiTERATURE
}

\author{
Ellie L. Grushcow ${ }^{a, c}$ and Patricia K. Sheridan ${ }^{b, c}$ \\ ${ }^{\mathrm{a}}$ Division of Engineering Science, ${ }^{\mathrm{b}}$ Institute for Studies in Transdisciplinary Engineering Education and Practice, \\ ${ }^{\mathrm{c}}$ Troost Institute for Leadership Education in Engineering, University of Toronto \\ ellie.grushcow@mail.utoronto.ca, patricia.sheridan@utoronto.ca
}

\begin{abstract}
This paper explores the way in which three graduate attributes have been instructed on, together, in the undergraduate engineering curriculum. In particular, this paper explores how teamwork, ethics \& equity, and the impact of engineering on society and the environment are taught together. These three attributes are used as a framing for engineering leadership education to explore how it has been embedded in the curriculum from a graduate attributes perspective.

Following systematic literature review principles, this work explores the prevalence and motivations for incorporating these attributes in undergraduate engineering education in Washington Accord signatory countries. Findings indicate that these attributes are not frequently documented as being taught together, and are motivated equally as a design topic as a leadership/entrepreneurship topic.
\end{abstract}

Keywords: Graduate attributes, teamwork, ethics and equity, impact of engineering on society, leadership.

\section{INTRODUCTION}

This work seeks to understand current practices and trends in teaching a combination of the CEAB graduate attributes "(Individual and) Team Work," (TW) "Ethics and Equity," (E\&E) and "Impact of Engineering on Society and the Environment." (IESE), (

Fig. 1) [1]. Specifically, we ask: "how are teamwork skills, ethics and equity, and impact on society and the environment explicitly taught together in undergraduate engineering education?"

Since 2015, the accreditation of Canadian engineering programs has centered on twelve 'graduate attributes [2],' overarching groups of characteristics that graduates of accredited programs should develop. These attributes are derived from the Washington Accord, an international agreement between countries ensuring that qualifications from their respective engineering schools are “comparable" and "substantially equivalent [3]."

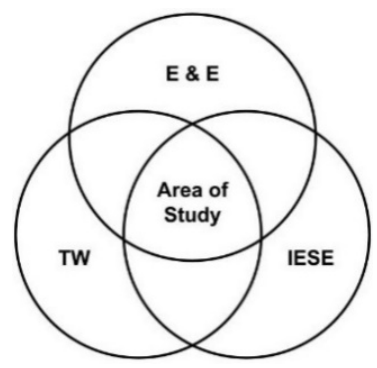

Fig. 1. Visual representation of the area of interest to this paper.

The ability to positively influence change through engineering work requires that engineering students develop the capacity to work effectively with each other and account for the ethical, equitable, societal and environment considerations in their work processes and products. At the Troost Institute for Leadership Education in Engineering (ILead) we focus on the role of understanding self (values, beliefs, motivations) as a way of developing the capability to lead in teams, groups, projects and more broadly in society [4]. Central to this is the philosophy that an individual's identity will influence the way in which they practice engineering.

Using the CEAB graduate attributes as a frame, we sought to understand how others were incorporating leadership education in their engineering curriculums through these three attributes. Our goal was to consolidate knowledge of current practice and organize it so that we and other practitioners could use this as a way to explore possible leadership integration paths in the future. This paper focuses in on three attributes that are connected to good engineering leadership.

The use of the graduate attributes as a frame was selected as a potential integration pathway to bring leadership education into the core curriculum. Given that engineering courses already need to incorporate these attributes, could the integrated inclusion of them afford 
leadership development? Klassen et. al. discuss the need to move leadership education into the core curriculum as a way of demonstrating its importance while dealing with curriculum that is already full [5], while Schell et. al. share ways that this has been done across three Washington Accord signatory countries [6]. At Troost ILead, our instruction on leadership is often described as covering the three graduate attributes under study. This has enabled us to integrate leadership instruction more readily into the core curriculum (e.g. [7], [8]).

Meta-analyses of how these attributes are taught (e.g. [9], [10], [11]), and of how engineering leadership is taught (e.g. [12]) are prevalent in the literature. However, these papers either look at the attributes in isolation, or explore how leadership is taught in a way that does not have a direct connection to the attributes. For example, a systematic review around ethics instruction discovered that it was readily incorporated in the interventions it analysed because it was already a required component of the programs [11]. While these meta-analyses provided opportunities to explore the instruction/inclusion of these attributes in isolation, they do not provide a way to use the graduate attributes to motivate inclusion of leadership instruction in an interconnected manner. As a result, we sought to conduct a structured review of the literature on the graduate attributes to explore how these attributes were taught together, and whether those instructional interventions were considered leadership instruction by their authors.

As a result, this paper presents a structured review of the literature describing teaching interventions in undergraduate engineering settings aimed at teaching all three of these attributes to students in conjunction.

\section{Methods}

The literature review was conducted according to systematic principles. Search terms (Appendix A) representing the research question were developed collaboratively by the authors with input from one of the research librarians.

\subsection{Database Selection}

Six databases were selected for the search on the advice of our research librarian. In each database chosen, the same search should always produce the same results, supporting the replicability of the research and its potential future extension. In order to address the multidisciplinary nature of the research question, two engineering databases (IEEE Xplore and Compendex), two general science databases (Scopus and Web of Science) and two education databases (ERIC and Education Source) were selected.

\subsection{Result Restriction}

Where possible, results were actively limited to English-language results from 2010 or later, and to results that included the search terms in the subject, title, or abstract of a document. Our interest was limited to 2010 or later, to focus on interventions that occurred with relatively 'modern' technology and educational research at hand. Since two-thirds of the Washington Accord's full participants joined the accord before 2010 [3] and had therefore had the incentive to teach the attributes well established, it follows that the literature after this point should represent accreditation based attribute inclusion. In order to gather a broad range of ideas, we have chosen to include work done not only in Canada where the CEAB attributes specifically apply, but to include work done in any country that was a signatory of the Washington Accord at the time the work was conducted. The results of each search conducted were transferred into Mendeley as. bib or .ris files, allowing duplicate documents to be eliminated.

\subsection{Selection Criteria}

Abstracts for each document returned were read by the first author to sort the papers into 'maybes' and definite 'nos.' Documents in the 'maybe' category were examined in full to determine whether they met the predetermined inclusion and exclusion criteria written collaboratively by the authors. The inclusion criteria are included in Table 1 with the associated exclusion criteria being the inverse of the criteria. Most crucial was the requirement that the intervention included the "explicit instruction" relating to each attribute, meaning that a framework of the concept is introduced in addition to students' [practical] experience with the concept. Decisions about the inclusion and exclusion of documents were made independently by the first author except in cases of uncertainty, when the second author was consulted, and consensus was reached through discussion.

Table 1: Inclusion criteria used in article selection.

\begin{tabular}{l}
\hline Inclusion \\
\hline $\begin{array}{l}\text { Intervention was conducted in a country was a signatory of } \\
\text { the Washington Accord when the intervention occurred }\end{array}$ \\
\hline $\begin{array}{l}\text { An intervention was conducted and described on a per- } \\
\text { course basis }\end{array}$ \\
\hline $\begin{array}{l}\text { Teamwork skills, ethics, and impact on society were } \\
\text { explicitly included in the intervention }\end{array}$ \\
\hline $\begin{array}{l}\text { The intervention must include explicit instruction in each } \\
\text { concept it includes }\end{array}$ \\
\hline Source is from 2010 or later \\
\hline Rationale for the intervention was discussed in the paper \\
\hline $\begin{array}{l}\text { Intervention is conducted in an undergraduate engineering } \\
\text { setting }\end{array}$ \\
\hline
\end{tabular}

\subsection{Data Collection and Analysis}

Data collection focused on the dimensions of the inclusion criteria. In particular, for each article data was collected on the context of an intervention, the specific pedagogical choices made and on the stated motivations for 
the intervention being conducted in the way that it was. Articles that met all inclusion criteria were then compared to elicit descriptive characteristics of the interventions and whether there was a perceived connection to leadership by the authors. These characteristics included: year of intervention, location of intervention in the curriculum, other concepts the intervention is integrated with, and the pedagogical strategies employed in the intervention. Only a descriptive comparison of the articles was completed.

\section{RESULTS}

Papers that met all the inclusion criteria are discussed herein, explored along the dimensions of analysis.

\subsection{Search Counts and Distribution}

The search for articles that included all three attributes resulted in low returns. As can be seen in Fig. 2, interventions that discussed only one or two of the attributes together resulted in substantially higher returns. In IEEE Xplore, the search for all three attributes yielded 54 results. Using Compendex yielded 337 results, using Scopus yielded 17 results, using Web of Science yielded 119 results, using ERIC yielded 71 results, and using Education source yielded 63 results. After duplicates were removed, the final number of total results was 592. Of these, six fit the inclusion and exclusion criteria (Table 1). Given the specificity of the criteria combined with lack of explicit instruction on 'soft skills' in some engineering curricula, this low number is not entirely surprising.

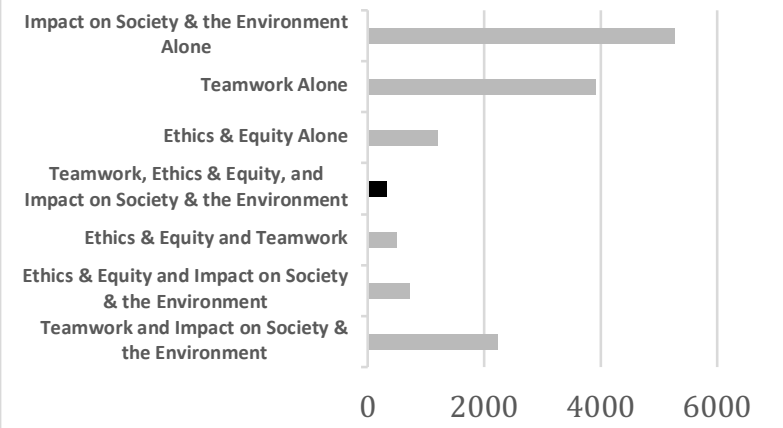

Fig. 2. Number of articles returned in Compendex for different combinations of the three attributes. Compendex searches were very similar to those in other databases in terms of the distribution of results, but as the overall number of results from Compendex was the largest it is taken as an example here.

\subsection{Papers that met Criteria}

The six papers that met our inclusion and exclusion criteria are briefly summarised to provide context for the further discussion.

A. Gerhart et al. [13] present a second-year course from a four-year sequence that was developed as part of an initiative to include more entrepreneurial and leadership skills in the curriculum. Students had instruction on all of the attributes in lecture, followed by short activities. Assessment was done through a longer-term team project and reflection exercises.

E. Andrijcic \& J. Williams [14] present a two-hour workshop open to any undergraduate students in which students go through a dramatic simulation with the goal of teaching crisis leadership skills. The exercise requires teamwork and centers on ethical and equitable decision making based on the impact on society and the environment of the choices made. The simulation is followed by a debrief in which reflection and explicit instruction occur.

J. L. Brugnano et. al. [15] present a fourth-year professional skills course intended to supplement a simultaneous laboratory and design skills course. Lectures on all three of the attributes as they apply to biomedical engineering were followed by individual and team in-class assignments which were reworked until they met expected standards based on instructor feedback.

K. G. Gipson et. al. [16] present a stand-alone course in first year, in which upper year students work as mentors to instill leadership skills in younger students. Students had instruction on all three of the attributes in lecture, as well as assessment of them through a design project and peerassessment. Feedback and support were provided by upper years throughout.

M. Duffy [17] presents a stand-alone course in third year focused on teaching the "soft skills" needed in professional life. Lectures were given on teamwork and ethics, where ethics included considerations of impact on society and the environment. These were paired with team activities, design projects, and case study analysis.

T. Favaloro et. al. [18] present a stand-alone course in fourth year intended as an industry-realistic capstone design course. The project is supplemented by lectures, small group meetings, and written reflection. Students were asked throughout the project to thoughtfully apply teamwork strategies and to explicitly consider their ethical responsibilities, as well as the impact their project would have on society and the environment.

\subsection{Pedagogical Strategies}

Different pedagogical strategies were employed depending on the goals of the instructor, (Fig. 3). Pedagogical strategies constituted instructional activities that worked to introduce, reinforce, or assess skills.

The most popular strategy was a lecture, used in all of the interventions other than E. Andrijcic \& J. Williams' [14] who used an intensive workshop focused on classroom discussion of topics. Close behind lectures were group projects and team tasks, at least one of which was used in every intervention. Group projects refer to more complex tasks lasting several classes, such as the design projects in the interventions presented by T. Favaloro et. al. [18] and 
K. G. Gipson et. al. [16]. Team tasks were shorter and less complicated exercises, completed during a single class or session. M. Duffy [17] and A. Gerhart et. al. [13] used short activities and games as an opportunity for students to start testing their teamwork skills, while E. Andrijcic \& J. Williams [14] centered their intervention on an involved, two hour simulation in which students had to apply knowledge of all three of the attributes under pressure. This simulation was followed by a reflective discussion, showcasing the utility of combining multiple strategies.

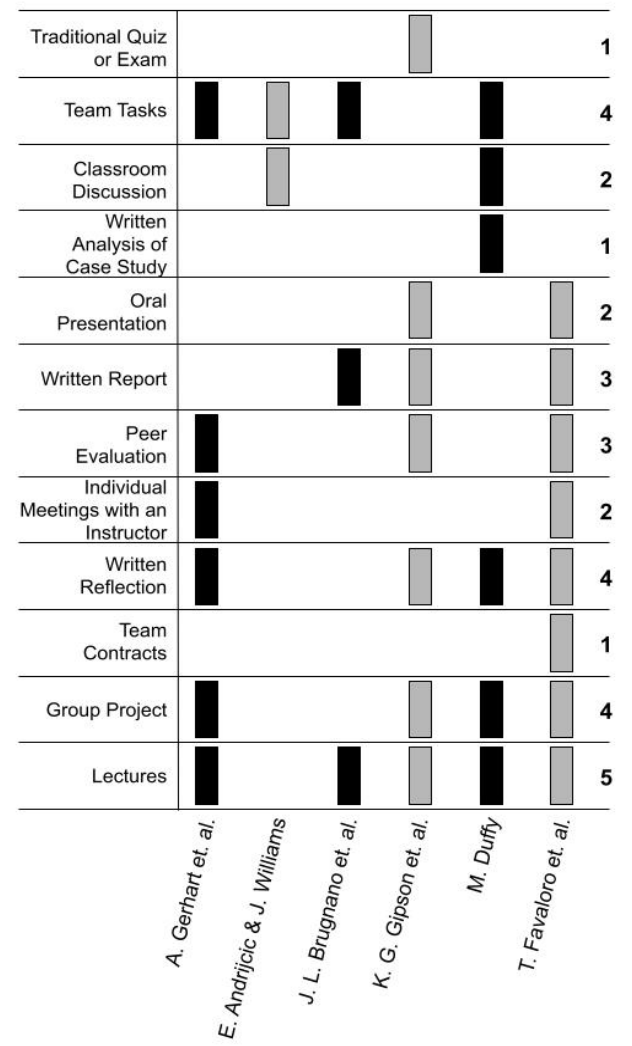

Fig. 3. List of pedagogical strategies found and the interventions in which they were applied. Total counts for the number of times each strategy was seen can be found on the right.

Written reflections were another popular tool, being used in four of the six interventions. These could be created individually as with K. G. Gipson et. al.'s [16] personal statement exercise and M. Duffy's [17] teamwork selfevaluation, but they could also be done in a group. In T. Favaloro et. al.'s [18] course "Team members together reflect on past team experiences (the most recent being the mock project) to reinforce the fact that each member is united in a common effort[...] [18]"

\subsection{Integration with Other Topics}

In the case of these six papers, two taught just the three attributes, without another focus to juggle (E. Andrijcic \& J. Williams [14] and A. Gerhart et. al. [13]). The other four included various combinations of introductory knowledge of different engineering disciplines (K. G. Gipson et. al. [16] and M. Duffy [17]), and engineering design education (J. L. Brugnano et. al. [15], M. Duffy [17], and T. Favaloro et. al. [18]).

The engineering skills being taught alongside the attributes can be closely tied to how the attributes themselves were being taught. For example, in T. Favaloro et. al.'s [18] intervention, the model of teamwork used is tailored to the design-consulting-type work students will likely encounter post-graduation. Students participate in a hierarchical team structure in which they meet with a mock manager (instructor) once a week for work review. Further constraints on the design project help students gain practical experience in ethical decision-making and understanding their impact on society and the environment through accounting for these considerations when developing their problem statement and possible design solutions. In this intervention, learning the attributes is part of learning about a design process.

However, when the attributes were taught apart from other graduate attributes, they were still taught in an engineering context. In E. Andrijcic \& T. Williams' [14] intervention, one of the goals was to "[show students] that many of the leadership assumptions that hold true in business-as-usual situations are violated in a crisis," which was achieved by putting students through crisis simulations based on real-world events where an engineer or scientist could realistically be in the room [14].

\subsection{Connection to Leadership and Equity}

Of the six papers that met the inclusion criteria, two papers explicitly stated that leadership skill development was a goal of the intervention: E. Andrijcic \& J. Williams' [14], and K. G. Gipson et. al. [16]. Entrepreneurship skills were a motivator in two other papers: T. Favaloro et. al. [18] and A. Gerhart et. al. [13]. Design education and professional responsibility were the core motivators in the remaining two papers: M. Duffy [17] and J. L. Brugnano et. al. [15].

None of the six papers found mentioned equity explicitly. When equity was considered at all, it was not uniquely tied to ethics. In E. Andrijcic \& J. Williams' [14] intervention, ethics, equity, impact on society, and impact on the environment were all grouped together as a conception of what it meant to make 'good' decisions. In K. G. Gipson et. al.'s [16] intervention, equity concerns appear as a focus on respect for diversity as a leadership attribute separate from skillful ethical decision making.

\subsection{Locations of the Intervention}

The number of results returned within a given publication year was relatively even. Of the six documents being examined in this paper, two were published in 2010 (M. Duffy [17] and A. Gerhart et. al. [13]), one in 2012 (J. 
L. Brugnano et. al. [15]), one in 2015 (K. G. Gipson et. al. [16]), one in 2016 (E. Andrijcic \& J. Williams [14]), and one in 2018 (T Favaloro et. al. [3]).

Of the 6 interventions that met the criteria, 5 were mandatory for the participants, the exception being E. Andrijcic and T. Williams' [14]. The years of study of the interventions are shown below in Fig. 4, where the only intervention that was designed to work across all years was the one elective intervention.

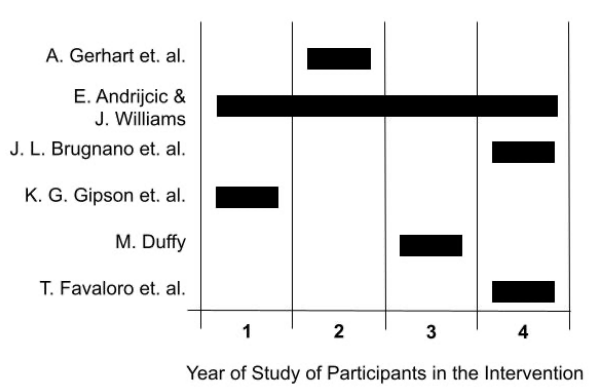

Fig. 4. Year of study of the participants in each intervention analysed. The spread across the curriculum was quite even.

Of the 6 interventions analysed, 5 described interventions conducted in the United States and one (by M. Duffy [17]) described an intervention conducted in Ireland. No interventions in Canada met the inclusion/exclusion criteria from the search locations.

\subsection{Motivation for Intervention}

The authors were interested in the motivations for implementing such interventions, Fig. 5. To this end, quotes were collected describing the motivations for each intervention.

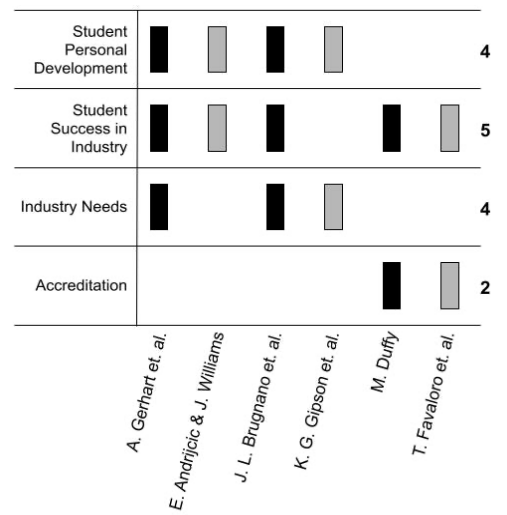

Fig. 5. Motivations by intervention. Total numbers motivated by each factor are listed on the right.

Accreditation was not a large motivator for the inclusion of these attributes in the interventions. It is interesting to note that only two papers explicitly stated accreditation as a motivator, and did not list it as a sole motivator [17], [18].
The skills needed in/for industry and setting students up for success in this context was a motivator in all 6 papers.

\section{DISCUSSION}

\subsection{Ethics (not Equity) Instruction}

Ethics - not equity - was the focus of instruction in the papers that incorporated $\mathrm{E} \& \mathrm{E}$ concepts. In the two papers that did include it [14], [16], when equity was a focus it was considered as a component of good decision making, teamwork or leadership; not a concept connected to ethics. Given that the majority of these interventions were completed in the US, where ABET explicitly asks for ethics but not equity as part of its accreditation criteria [19], it is hypothesized that this may have influenced its lack of inclusion.

In Canada, the pairing of equity with ethics instruction has created a unique context for the instruction of this attribute. Overall, instruction on equity is lacking in engineering education curriculum [20]; the primary focus is on incorporating ethics, and usually in a Professional Engineering context. Our hope in integrating E\&E with the teamwork attribute was that we would see a context and approach to incorporating equity that was people and leadership focused - something we only saw in two of the papers.

\subsection{The Pressure of Including Multiple Attributes}

In our own institution, both the practical constraints of the existing timetable and thoughtful, pedagogical decision-making must always be considered when new interventions are introduced into the curriculum. It is likely that those same pressures were at play when each of these six interventions was conceived, as only one course-based intervention introduced these three attributes in the absence of any other technical engineering instruction [13]. The variety of placements of interventions within and alongside the curriculum suggest that those unique pressures in each institution lead to a unique outcome in terms of when an intervention is conducted. They also imply that interventions should be able to be integrated into the curriculum wherever possible; they can be made appropriate and helpful for whichever stage of education the participants are at.

\subsection{Discussion of Pedagogical Strategies}

The popularity of lectures as a tool is probably due to their place as the most immediately obvious way to provide a large number of students with explicit instruction as a base for other learning. However, this leads to the possibility of the attributes being all taught within the same context (project), but appearing as different streams of instruction (taught in different stand-alone lectures). Only in assessment (report or reflection writing) or 
conversational debriefs were the attributes interconnected in a single strategy. Using the context as a way to connect the attributes can limit the understanding of the causal relationships between the attributes, and in particular limit the understanding of how equity, ethics, and society at large impact on teamwork structures and processes.

\subsection{Motivations to Incorporation}

Given that only two papers presented the accreditation process as a motivator for including these attributes, it is possible that accreditation may not be an effective way to motivate increased leadership education in the curriculum. Finding other motivational strategies connected to industry needs and student success in that context may be a more effective way of expanding leadership instruction.

\subsection{Conference Proceedings vs. Journals}

All six of the papers reviewed were from conference proceedings rather than journals. This may suggest that the kinds of descriptive writings we were seeking in this literature review are more welcome in a conference context than they are in a journal, which may favour papers that consider a controlled experiment. It also suggests that efforts to extend this research should focus on conference proceedings, and potentially also on directly examining the syllabi of engineering courses in a systematic way.

\section{LIMITATIONS}

\subsection{Replicability}

Although the use of only one reviewer for most of the decision-making process limits the replicability of the study, we feel that in the context of a search for pedagogical inspiration rather than specific data this limitation is acceptable.

\subsection{Generalizability}

As twenty-one countries are full participants in the Washington Accord [3], the specific contexts of Ireland and the Unites States should be considered thoroughly when transferring ideas and general information gleaned from this work even into other Washington Accord contexts, as they are not representative of the full diversity of the Washington Accord signatories.

While the sample size prevents us from drawing any broad conclusions about the state of teaching strategies for this combination of attributes, the interventions examined demonstrate ways in which the attributes can be connected in instruction.

\subsection{Lack of Canadian Representation}

It is important to note that none of the articles that met the inclusion criteria discussed interventions conducted in Canada. As a result, the location(s) of the search should be expanded in future work. It is possible that Canadian interventions are not being indexed readily in the search engines used because they are being published elsewhere.

\section{CONCLUSION}

A structured review of the literature on teamwork, ethics \& equity, and the impact of engineering on society $\&$ the environment was conducted to determine how these attributes are taught together. Although only six interventions were found in accordance with our inclusion and exclusion criteria, this review has still uncovered ways to address the teaching of these attributes to undergraduate engineering education. Across all interventions the context of a project or situated experience was found to be the most common way to link the attributes in the interventions. Motivations to include instruction on these skills did not primarily stem from accreditation but other motivators related to leadership and student success in industry.

Future research might include a broader review, focusing on interventions in which only two of the attributes are being taught together.

\section{Acknowledgements}

This research was supported by a Dean's Emerging Innovation in Teaching Professorship. Many thanks to Mindy Thuna for her support as our research librarian, and to the Troost ILead Summer Research Group for their feedback.

\section{References}

[1] Engineers Canada Consultation Group on Engineering Instruction and Accreditation, "Graduate Attributes," 7 Janruary 2016. [Online]. Available: https://engineerscanada.ca/sites/default/files/GraduateAttributes.pdf. [Accessed 22 August 2020].

[2] M. Isaacson, "Graduate attributes and accreditation," Canadian Civil Engineer, pp. 19-21, 2016.

[3] Engineers Canada, "The Washington Accord," [Online]. Available: https://engineerscanada.ca/accreditation/thewashington-accord. [Accessed 31 July 2020].

[4] Troost ILead, "Troost ILead," [Online]. Available: https://ilead.engineering.utoronto.ca/files/2013/07/ILeadVisioneering-Nov-2012.pdf. [Accessed 05 May 2021].

[5] M. Klassen, D. Reeve, G. J. Evans, C. Rottmann, P. K. Sheridan and A. Simpson, "Engineering: Moving Leadership From the Periphery to the Core of an Intensely Technical Curriculum," New Directions for Student Leadership, vol. 165, pp. 113-124, Spring 2020.

[6] W. J. Schell, B. E. Hughes, J. Donald, T. Goldfinch, A. Kadi, E. Moore, D. Reeve, C. Rottmann and P. K. Sheridan, "Leadership transcending borders: Building bridges to integrate technical and professional knowledge," in Canadian Engineering Education Association Annual Conference, Montreal, Canada, 2020. 
[7] G. Evans, D. Reeve, P. K. Sheridan, M. McGuire, K. Minella, E. Oliva-Fisher, L. Wilkinson and T. McAlary, "Incorporating team-effectiveness as a learning objective in the design project within a technical core course," in Canadian Engineering Education Association Annual Conference, Montreal, Canada, 2013.

[8] N. Walji, P. K. Sheridan, P. Kinnear, R. Irish and J. Foster, "Who You Are and How You Work - Embedding Positionality in Engineering Design," in Canadian Engineering Education Association Annual Conference, Montreal, Canada, 2020.

[9] M. Borrego, J. Karlin, L. D. McNair and K. Beddoes, "Team Effectiveness Theory from Industrial and Organizational Psychology Applied to Engineering Student Project Teams: A Research Review," Journal of Engineering Education, vol. 102, no. 4, pp. 472-512, 2013.

[10] C. Rottmann, D. Reeve, R. Sacks and M. Klassen, "Engineering Ethics Education: More than a CEAB Requirement," in Canadian Engineering Education Association Annual Conference, Hamilton, Canada, 2015.

[11] J. L. Hess and G. Fore, " Systematic Literature Review of US Engineering Ethics," Science and Engineering Ethics, vol. 24, pp. 551-583, 2017.

[12] M. Klassen and J. Donald, "Developing a Taxonomy to Compare Engineering Leadership Curricula Across Canadian Universities," Canadian Journal of Science Mathematics and Technology Education, vol. 20, no. 2, 2020.

[13] A. Gerhart, D. Carpenter, M. Grunow and K. Hayes, "Development of a leadership and entrepreneurship skills assessment instrument," in ASEE Annu. Conf. and Expo., Louisville, 2010.

[14] E. Andrijcic and J. Williams, "'I Survived the Crisis!' Using Real World Scenarios to Teach Crisis Leadership Skills to Undergraduate Engineering Students," in ASEE Annu. Conf. and Expo., New Orleans, 2016.

[15] J. L. Brugnano, "Scaffolding and assessing professional design skills using an active-learning studio style classroom," in ASEE Annu. Conf. and Expo., San Antonio, 2012.

[16] K. G. Gipson, M. Daly, C. Jahan, T. Ware, D. L. FoucarSzocki and J. J. Henriques, "Development of the James Madison University Undergraduate Engineering Leadership Program," in ASEE Annu. Conf. and Expo., Seattle, 2015.
[17] M. Duffy, "Experiences in Integrating Professional Studies into the Electrical \& Electronic Engineering Syllabus," in IEEE Transforming Engineering Education: Creating Interdisciplinary Skills for Complex Global Environments, Dublin, 2010.

[18] T. Favaloro, P. E. Mantey, S. C. Petersen and J. F. Vesecky, "Preparation of the professional engineer: Outcomes from 20 years of a multidisciplinary and crosssectoral capstone course," in ASEE Annu. Conf. and Expo., Salt Lake City, 2018.

[19] ABET, "Criterion 3 \& 5 Comparison Charts for the Engineering Accreditation Commission," 2017. [Online]. Available: https://www.abet.org/wp-content/uploads/ 2018/03/C3_C5_mapping_SEC_1-13-2018.pdf. [Accessed 7 March 2021].

[20] C. Rottmann and D. Reeve, "Equity as Rebar: Bridging the Micro/Macro divide in Engineering Ethics Education," Canadian Journal of Science Mathematics and Technology Education, vol. 20, pp. 146-165, 2020.

\section{Appendix A: SEARCH TERMS}

Table 2: Search terms corresponding to each part of the research question.

\begin{tabular}{|l|l|l|l|}
\hline \multicolumn{1}{|c|}{ Teaching } & \multicolumn{1}{|c|}{ Teamwork } & \multicolumn{1}{c|}{ Ethics } & Equity \\
\hline Teach & Team & Ethical & Equality \\
\hline Instruct & Group & Moral & Equal \\
\hline Instructing & Groupwork & Morality & \\
\hline Education & Collaborate & Value & \\
\hline Learn & Collaboration & Values & \\
\hline Learning & Collaborating & & \\
\hline & Work together & & \\
\hline & Working together & & \\
\hline
\end{tabular}

\begin{tabular}{|l|l|l|}
\hline $\begin{array}{l}\text { Society (\& the } \\
\text { Environment) }\end{array}$ & Undergraduate & Engineering \\
\hline Societal & Undergrad & Engineer \\
\hline Social & Undergraduates & Engineers \\
\hline Socioeconomic & Undergrads & Engineering student \\
\hline Sociopolitical & & Student engineer \\
\hline Sociocultural & & $\begin{array}{l}\text { Engineering } \\
\text { students }\end{array}$ \\
\hline Environment & & Student engineers \\
\hline Environmental & & \\
\hline
\end{tabular}

